\title{
Nano-safety Research: Examining the Associations among the Biological Effects of Nanoparticles and Their Physicochemical Properties and Kinetics
}

\author{
Kazuma Higashisaka, ${ }^{*, a}$ Kazuya Nagano, ${ }^{a}$ Yasuo Yoshioka, ${ }^{a, b}$ and Yasuo Tsutsumi ${ }^{a, c}$ \\ ${ }^{a}$ Graduate School of Pharmaceutical Sciences, Osaka University; 1-6 Yamadaoka, Suita, Osaka \\ 565-0871, Japan: ${ }^{b}$ BIKEN Center for Innovative Vaccine Research and Development, The Research \\ Foundation for Microbial Diseases of Osaka University; 3-1 Yamadaoka, Suita, Osaka 565-0871, \\ Japan: and ${ }^{c}$ The Center for Advanced Medical Engineering and Informatics, Osaka University; \\ 1-6 Yamadaoka, Suita, Osaka 565-0871, Japan.
}

Received October 31, 2016

\begin{abstract}
In the past decade, nanotechnology has advanced rapidly, and many products containing nanoparticles are now an important part of our daily lives. Despite our increasing exposure to nanoparticles, however, information regarding the absorption, distribution, metabolism, excretion, and toxicity of nanoparticles remains limited. In this review, we introduce our group's ongoing research into the biological effects and toxicities of nanoparticles, which we broadly refer to as "nano-safety research." In addition to determining the biological effects of nanoparticles and elucidating the underlying mechanisms of those effects, we are also exploring the associations among the physicochemical properties and kinetics of nanoparticles. Furthermore, we are currently developing a battery of biomarkers that we hope will be used to predict the biological effects of nanoparticles during the early stages of development. Our research provides valuable basic information on the safety of nanoparticles. We hope that this information will be used for the development of better assessments of nanoparticles safety and for the creation of more appropriate regulations to ensure not only the safety but also the sustainability of nanotechnology.
\end{abstract}

Key words nanoparticle; hazard; physical property; kinetics; real-world exposure

\section{INTRODUCTION}

We are exposed on a daily basis to a wide range of natural and man-made particulate matter in the environment. The health hazards associated with exposure to particulate matter have long been recognized; for example, exposure to fine particles (particulate matter with a diameter of $2.5 \mu \mathrm{m}$ or less) is associated with the onset or worsening of cardiovascular disease and with premature mortality, and exposure to fine crystalline silica (less than $5 \mu \mathrm{m}$ ) is associated with the development of pneumoconiosis, an occupational lung disease commonly found among workers in the mining industry. ${ }^{1,2)}$ The negative health effects of exposure to fine particles are thought primarily to be the result of the biological effects of particles at the lower end of the particle size distribution, in particular those in the nano-size range (diameter, $1-100 \mathrm{~nm}$ ). Therefore, research into the biological effects of nanoparticles is now attracting considerable attention., ${ }^{3,4)}$

Nanoparticles are important materials because they have unique physicochemical properties compared with the bulk or sub-micron-sized material. For example, at the nanoscale, materials can acquire unique electrical properties or increased liquidity and reactiveness due to quantum effects, and these properties make nanoparticles indispensable for the manufacture of many products. ${ }^{5,6)}$ Examples of nanoparticles currently used in manufacturing are nano-sized titanium dioxide and platinum nano-colloids, which are used to make cosmetic foundations and sunscreens, and amorphous silica nanoparticles, which are used to make anti-caking agents and as a food additive. ${ }^{78}$ Indeed, the Project on Emerging Nanotechnologies' website (http://www.nanotechproject.org, accessed Dec.
2016), which is administered by the Woodrow Wilson International Center for Scholars, lists 118 nanoparticle-containing food and cooking supplies that are currently in manufacture, and the number is likely to rapidly increase in the future.

\section{SAFETY OF NANOPARTICLES}

Although nanoparticles have many useful properties, there are concerns that these same properties may increase the toxicity of nanoparticles compared with that of the bulk material. ${ }^{9,10)}$ The current laws and regulations covering the safe use of chemicals refer only to a chemical's structural formulae; therefore, if the bulk or submicron-sized material is deemed safe, the nano-sized material is also assumed to be safe. This means that little information on the specific safety of nanoparticles is available, so nanoparticle-specific risk analyses are urgently needed. Furthermore, we must elucidate not only the biological effects of nanoparticles but also how their physicochemical properties, such as particle size and surface properties, affect their kinetics in vitro and in vivo.

To this end, our group is conducting ongoing research into the biological effects and toxicities of nanoparticles, which we broadly refer to as "nano-safety research," where we are conducting absorption, distribution, metabolism, excretion, and toxicity (ADMET) analyses to qualitatively and quantitatively determine the kinetics of nanoparticles in vitro and in vivo and to identify any hazards posed by nanoparticles to human health and the environment (Fig. 1). Several of our studies in mice have revealed important information. For example, we have reported that amorphous silica nanoparticles (diameter less than $100 \mathrm{~nm}$ ), unlike the bulk material, can enter the sys- 

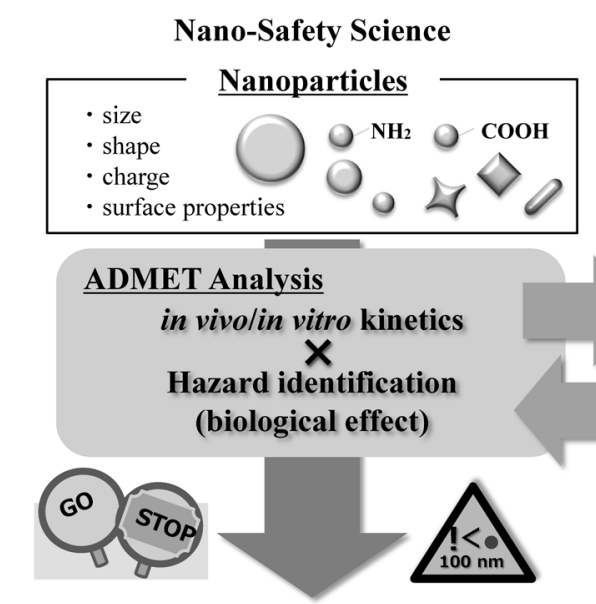

Risk Analysis/Risk Evaluation

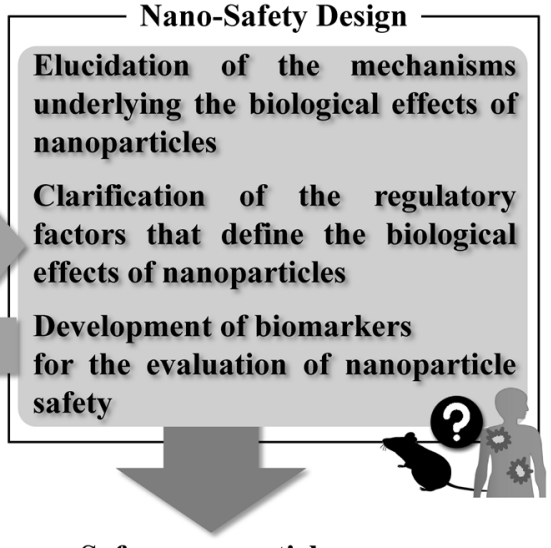

$\underline{\text { Safer nanoparticles }}$

\section{Nano-safety science and nano-safety design research for the development of sustainable nanotechnology}

Fig. 1. Nano-safety Science and Nano-safety Design Research

Our group is engaged in research using absorption, distribution, metabolism, excretion, and toxicity analyses to support the development of safe, sustainable nanotechnology.

temic circulation through the skin and nasal or oral mucosa and be distributed to several tissues such as liver or brain. ${ }^{11-13)}$ We have also reported that in mice silica nanoparticles with diameter of $70 \mathrm{~nm}$ can cross the placental barrier and migrate to the fetal brain and liver, ${ }^{14)}$ and that systemic administration of the silica nanoparticles impairs blood clotting, induces disseminated intravascular coagulation syndrome, and injures the placenta resulting in intrauterine growth restriction and developmental neurotoxicity in the fetus. ${ }^{14,15)}$

2.1. Size-Specific Biological Effects of Nanoparticles Generally, the biological effects of nanoparticles are considered to be a result of increased tissue penetration due to their decreased particle size compared with the bulk material. That is, the biological effects of nanoparticles increase as particle size decreases. However, it has been reported that the biological effects of nanoparticles can also decrease as particle size decreases and that these changes in the biological effects only occur with certain materials. For example, carbon nanotubes are carcinogenic when the particle size is $50 \mathrm{~nm}$, but not when it is 145 or $15 \mathrm{~nm}^{16,17)}$ Since the biological effects of nanoparticles cannot be fully explained by relative particle size alone, comparative analyses of microparticles and nanoparticles are insufficient to evaluate the biological effects of nanoparticles because such comparisons may lead to over- or underestimation of the risks.

Recently, we examined the relationship between particle size and acute toxicity of intravenously administered silica nanoparticles in mice (in submitted). We found that the severity of several acute toxicities such as acute lethal toxicity or liver damage increased as particle size decreased. However, we also found that change in rectal temperature, one of the parameter of acute toxicity we examined, had a bell-shaped distribution, where silica nanoparticles with larger or smaller diameters than the mean had progressively less effect on rectal temperature, further demonstrating that not all toxicities associated with exposure to nanoparticles follow the paradigm that toxicity increases as particle size decreases. Thus, nanoparticle safety analyses not only should examine the toxicities associated with particles of specific sizes but also should examine how particle size is related to the severity of toxicities.

2.2. Reproductive Toxicity of Nanoparticles Fetuses and infants are particularly vulnerable to the effects of nanoparticles because their defense mechanisms, such as the blood-brain barrier and the immune system, are not yet fully developed. ${ }^{18,19)}$ In fact, nanoparticles may be toxic to fetuses and infants at concentrations that have no negative effects in adults. ${ }^{19-21)}$ Epidemiological studies in women have revealed that repeated exposure to particulate matter with a diameter of $2.5 \mu \mathrm{m}$ or less during pregnancy or lactation increases the risk of children developing an autism spectrum disorder, and studies in men have revealed that repeated exposure to particulate matter with a diameter of $2.5 \mu \mathrm{m}$ or less may reduce

\section{Biography}

Kazuma Higashisaka, Ph.D., has been an Assistant Professor at Osaka University since 2012. He graduated from Osaka University in 2009, and received his doctoral degree from Osaka University in 2016. He was a Research Fellow of the Japan Society for the Promotion of Science (2012). He has been a recipient of the Kinki Branch of Pharmaceutical Society of Japan Award for Young Scientists (2013). Also, he was awarded the Best Poster Award of Safety of Engineered Nanoparticles and Nanotechnologies (2012) and the Best Poster Award of Personalized Medicine (2013).

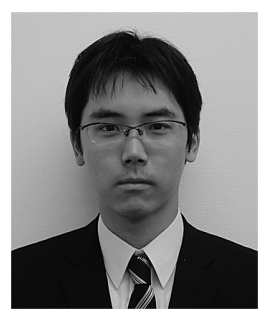

Kazuma Higashisaka 
sperm motility. ${ }^{22,23)}$ These results suggest that it is important to evaluate the impact of nanoparticles not only on the health of children but also on that of prospective parents.

2.2.1. Effects of Exposure to Silica Nanoparticles during Pregnancy

Several groups, including ours, have examined the toxicity of nanoparticles during pregnancy in mice. ${ }^{24,25)}$ We reported that mice intravenously exposed to silica nanoparticles with a diameter of $70 \mathrm{~nm}$ developed greater intrauterine growth restriction and placental damage than those exposed to silica particles with diameters greater than $100 \mathrm{~nm}$, suggesting that pregnancy complications may result from the nanoparticles causing greater damage to the placenta than the bulk material. ${ }^{14)}$

The movement of nanoparticles across the placental barrier is also thought to be an important way nanoparticles induce pregnancy complications. ${ }^{26,27)}$ We reported that heparin, which prevents complement activation and is a placental growth factor, ${ }^{28,29)}$ prevented the decrease of fetal weight caused by intravenous exposure of pregnant mice to silica nanoparticles with a diameter of $70 \mathrm{~nm}$, suggesting that pregnancy complications associated with exposure to silica nanoparticles with a diameter of $70 \mathrm{~nm}$ are a result of increased coagulation, increased complement activation, and greater placental dysfunction. ${ }^{14)}$ Moreover, inflammation in pregnant mice is thought to be an important factor of nanoparticle-induced pregnancy complications. It has also been reported that silica nanoparticles increase the expression of nucleotide-binding oligomerization domain-like receptor family pyrin domaincontaining 3 in pregnant mice; knockout mice showed no placental inflammation or increased production of reactive oxygen species, suggesting that silica nanoparticle-induced pregnancy complications are related to the inflammasome. ${ }^{30)}$ In addition, we previously showed that intravenous exposure to silica nanoparticles with a diameter of $70 \mathrm{~nm}$ increases neutrophil count in mice, ${ }^{31)}$ which is the first line of defense against microbial infection during acute inflammation. ${ }^{32}$ We have also revealed that the silica nanoparticle induce neutrophilia in pregnant mice, suggesting that neutrophils might play some important role in the induction of complications during pregnancy.

2.2.2. Distribution of Nanoparticles in Breast Milk and the Effects of Silver Nanoparticles in Infants

Although breastfeeding, an important form of contact between mother and child, reduces the risk of morbidity and the development of asthma and diabetes, ${ }^{33)}$ breast milk is a major route of exposure to chemical substances in newborns. ${ }^{18,19)}$ Chemical substances ingested by the mother, such as polychlorinated biphenyls and dioxins, can be distributed to the breast milk leading to unintentional exposure of the infant. ${ }^{34,35)}$ Indeed, in mice, intravenously administered titanium dioxide nanoparticles with diameter of $8 \mathrm{~nm}$ and fullerenes have been shown to be transferred from dams to pups via breastfeeding. ${ }^{36-38)}$ Therefore, it is essential to examine infant exposure to nanoparticles via breastfeeding and breast milk. Studies are also needed to examine the potential for exposure of infants to nanoparticles at concentrations that are insufficient to cause biological effects in the mother, such as damage to the mammary gland.

To elucidate the physicochemical properties that determine whether nanoparticles are distributed to breast milk, our group has examined the exposure of mouse pups to silver nanopar- ticles through breast milk. ${ }^{39,40)}$ Silver nanoparticles have potent antibacterial activity and are used in the manufacture of many commercial products such as food utensils, clothing, and antibacterial sprays. After oral or intravenous administration of the silver nanoparticles to dams, we found that the silver nanoparticles were distributed to the pups via the breast milk and that this accumulation of the nanoparticles in breast milk may be a direct result of physicochemical properties such as particle size or the presence of surface modifications. In addition, although we found that orally treated silver nanoparticles with diameter of $10 \mathrm{~nm}$ distributed to the offspring via the breast milk migrated to the brain, we did not observe any effects on emotional cognitive function, even when the dams were exposed to nanoparticle concentrations. Since information on the safety of nanoparticles during breastfeeding is limited, our report provides valuable insights for future studies.

\subsubsection{Effects of Exposure to Silica Nanoparticles in} Males

Our group has also examined the reproductive toxicities of nanoparticles in males. Epidemiological studies have shown that exposure to particulate matter with a diameter of $2.5 \mu \mathrm{m}$ or less reduces sperm motility. ${ }^{22)}$ In addition, animal experiments have revealed that exposure to nanoparticle-rich diesel exhaust particles disrupts the secretion of sex hormones, and that injected silver nanoparticles $(20$ and $200 \mathrm{~nm})$ reduce sperm count, increase the rate of sperm malformation, and induce DNA damage in germ cells. ${ }^{41-43)}$ In addition to previous reports that some nanoparticles migrate to the testes, ${ }^{44,45}$ ) we have found that intravenously treated silica nanoparticles with diameter of $70 \mathrm{~nm}$ cross the blood-testis barrier and distribute in germ cells. ${ }^{46)}$ We have also observed the accumulation of the silica nanoparticles in Sertoli cells. Transcytosis is one mechanism by which silica nanoparticles, after uptake by cells, could be transferred across the blood-testis barrier. Recent reports have shown that fine particles such as titanium dioxide nanoparticle pass through and loosen gap junctions by acting on the structural proteins of adherens junctions between cells, such as vascular endothelial cadherin. ${ }^{47}$ Thus, silica nanoparticles may migrate to the testes by increasing the permeability of the epithelium. In future studies, we intend to elucidate the mechanisms underlying the movement of silica nanoparticles across the blood-testis barrier.

\section{DESIGN OF SAFER NANOPARTICLES}

Novel means of developing safe nanoparticles and evaluating their toxicity are urgently needed. Our group is currently accumulating information related to the development of safe nanoparticles, such as elucidating the mechanisms underlying their biological effects and developing biomarkers to assess their biological effects (Fig. 1). To improve the information available on the safety of nanoparticles, our group is conducting several ongoing qualitative and quantitative studies of the effects of exposure to nanoparticles.

3.1. Associations among the Physicochemical Properties and Biological Effects of Nanoparticles We previously reported that surface modification of silica nanoparticles, such as by the addition of amino or carboxyl groups, is a useful means of reducing their acute lethal and reproductive toxicities in mice and preventing their activation of the intrinsic coagulation cascade. ${ }^{14,48,49)}$ Also, we found that transition of 
nanoparticles into breast milk depends on their physicochemical properties; larger silver nanoparticles were more readily distributed to breast milk than were smaller nanoparticles, and the amount depended on the composition and surface characteristics of the nanoparticles. ${ }^{50)}$ We consider that this information about the associations among the physicochemical properties and biological effects of nanoparticles could lead to clarification of the regulatory factors that define the biological effects or in vivo/in vitro kinetics of nanoparticles.

In biological fluids, nanoparticles interact with biological components via a layer called the protein corona that forms around each nanoparticle, the composition of which is dependent on the physicochemical characteristics of the nanoparticles. ${ }^{51,52)}$ The protein corona is thought to confer nanoparticles with a biological identity that determines where they will localize and what biological effects they will have. Therefore, modulation of the protein corona represents a potential means of improving the safety of nanoparticles.

3.2. Biomarkers for Predicting the Biological Effects of Nanoparticles Our group is also attempting to establish methods to evaluate the biological effects of nanoparticles in animals by developing biomarkers using a proteomics-based approach. ${ }^{53,54)}$ Precisely predicting the biological effects of nanoparticles is difficult because they induce a wide variety of biological effects; therefore, we are also trying to develop biomarkers not only for proteins but also for bio-derived molecules such as microRNA. ${ }^{55)}$ Eventually, we hope to develop a battery of biomarkers that can be used to comprehensively screen nanoparticles for safety concerns during the early stages of development.

\subsection{Contribution of Nanoparticles to the Onset of} Disease Our group recently reported that silver nanoparticles can be used to sensitize mice to silver, suggesting that nanoparticles may play important roles in the establishment or onset of metal allergies. ${ }^{56)}$ The mechanism underlying the development of metal allergies remains unclear because examining sensitization in vivo is difficult. Therefore, in the future, we hope that our animal model of silver sensitization will help clarify the mechanisms underlying the development of metal allergies.

\section{DETERMINATION OF REAL-WORLD EXPOSURE TO NANOPARTICLES}

Recent qualitative clinical research has revealed that carbon nanotubes are sometimes present in the lungs of pediatric asthma patients. ${ }^{57)}$ In addition, oral absorption of pharmaceutical- or food-grade titanium dioxide particles has been demonstrated in humans. ${ }^{58)}$ Therefore, it is important to elucidate the association between the long-term tissue accumulation of nanoparticles and the onset of disease. Given that the health effects of exposure to nanoparticles may become evident only after long-term exposure, there is an urgent need to begin collecting information on the health effects of real-world exposure to nanoparticles in humans.

Conventional evaluation methods such as transmission electron microscopy or dynamic light scattering techniques are difficult to quantitatively evaluate the physicochemical characteristics of nanoparticles. Therefore, our group is attempting to establish a measurement technique that uses single-particle inductively coupled plasma mass spectrometry to quanti- tatively determine the physicochemical characteristics of metal-based nanoparticles that are known to accumulate in the human body. ${ }^{59)}$ Although the concentrations of nanoparticles in the environment are now being monitored more closely, the actual exposure of humans to nanoparticles remains unclear. $^{60,61)}$ Our analytical method combines the advantages of two conventional evaluation methods-quantitative and selective analysis of elements by means of inductively coupled plasma mass spectrometry, and evaluation of particle characteristics by means of dynamic light scattering-and we hope that this method will provide not only a means of identifying nanoparticles but also a means of quickly and easily determining real-world exposure values.

\section{CONCLUSION}

To develop sustainable nanotechnology, elucidation of the real-world exposure values and biological effects of nanoparticles in humans is important. This information will be valuable for nanoparticle risk analyses and the development of more appropriate government regulations. We hope that our achievements in this field will promote the development of safe, sustainable nanotechnology.

Conflict of Interest Y.Y. is employed by the Research Foundation for Microbial Diseases of Osaka University, Japan. All other authors declare no competing financial interests.

\section{REFERENCES}

1) Mills NL, Donaldson K, Hadoke PW, Boon NA, MacNee W, Cassee FR, Sandstrom T, Blomberg A, Newby DE. Adverse cardiovascular effects of air pollution. Nat. Clin. Pract. Cardiovasc. Med., 6, 36-44 (2009)

2) Brook RD, Rajagopalan S, Pope CA 3rd, Brook JR, Bhatnagar A, Diez-Roux AV, Holguin F, Hong Y, Luepker RV, Mittleman MA, Peters A, Siscovick D, Smith SC Jr, Whitsel L, Kaufman JD, American Heart Association Council on Epidemiology and Prevention, Council on the Kidney in Cardiovascular Disease, and Council on Nutrition, Physical Activity and Metabolism. Particulate matter air pollution and cardiovascular disease: An update to the scientific statement from the American Heart Association. Circulation, 121, 2331-2378 (2010).

3) Delfino RJ, Sioutas C, Malik S. Potential role of ultrafine particles in associations between airborne particle mass and cardiovascular health. Environ. Health Perspect., 113, 934-946 (2005).

4) Midander K, Elihn K, Wallen A, Belova L, Karlsson AK, Wallinder IO. Characterisation of nano- and micron-sized airborne and collected subway particles, a multi-analytical approach. Sci. Total Environ., 427-428, 390-400 (2012).

5) Kaur IP, Agrawal R. Nanotechnology: a new paradigm in cosmeceuticals. Recent Pat. Drug Deliv. Formul., 1, 171-182 (2007).

6) Martirosyan A, Schneider YJ. Engineered nanomaterials in food: implications for food safety and consumer health. Int. J. Environ. Res. Public Health, 11, 5720-5750 (2014).

7) Schilling K, Bradford B, Castelli D, Dufour E, Nash JF, Pape W, Schulte S, Tooley I, van den Bosch J, Schellauf F. Human safety review of "nano" titanium dioxide and zinc oxide. Photochem. Photobiol. Sci., 9, 495-509 (2010).

8) Peters R, Kramer E, Oomen AG, Rivera ZE, Oegema G, Tromp PC, Fokkink R, Rietveld A, Marvin HJ, Weigel S, Peijnenburg AA, Bouwmeester H. Presence of nano-sized silica during in vitro digestion of foods containing silica as a food additive. ACS Nano, $\mathbf{6}$, 2441-2451 (2012). 
9) Zhang M, Jin J, Chang YN, Chang X, Xing G. Toxicological properties of nanomaterials. J. Nanosci. Nanotechnol., 14, 717-729 (2014).

10) Khalili Fard J, Jafari S, Eghbal MA. A review of molecular mechanisms involved in toxicity of nanoparticles. Adv. Pharm. Bull., 5, 447-454 (2015).

11) Hirai $T$, Yoshikawa $T$, Nabeshi $H$, Yoshida $T$, Tochigi $S$, Ichihashi K, Uji M, Akase T, Nagano K, Abe Y, Kamada H, Itoh N, Tsunoda S, Yoshioka Y, Tsutsumi Y. Amorphous silica nanoparticles sizedependently aggravate atopic dermatitis-like skin lesions following an intradermal injection. Part. Fibre Toxicol., 9, 3 (2012).

12) Yoshida T, Yoshioka Y, Tochigi S, Hirai T, Uji M, Ichihashi K, Nagano K, Abe Y, Kamada H, Tsunoda S, Nabeshi H, Higashisaka $\mathrm{K}$, Yoshikawa T, Tsutsumi Y. Intranasal exposure to amorphous nanosilica particles could activate intrinsic coagulation cascade and platelets in mice. Part. Fibre Toxicol., 10, 41 (2013).

13) Yoshida T, Yoshioka Y, Takahashi H, Misato K, Mori T, Hirai T, Nagano K, Abe Y, Mukai Y, Kamada H, Tsunoda S, Nabeshi H, Yoshikawa T, Higashisaka K, Tsutsumi Y. Intestinal absorption and biological effects of orally administered amorphous silica particles. Nanoscale Res. Lett., 9, 532 (2014).

14) Yamashita K, Yoshioka Y, Higashisaka K, Mimura K, Morishita Y, Nozaki M, Yoshida T, Ogura T, Nabeshi H, Nagano K, Abe Y, Kamada H, Monobe Y, Imazawa T, Aoshima H, Shishido K, Kawai Y, Mayumi T, Tsunoda S, Itoh N, Yoshikawa T, Yanagihara I, Saito S, Tsutsumi Y. Silica and titanium dioxide nanoparticles cause pregnancy complications in mice. Nat. Nanotechnol., 6, 321-328 (2011).

15) Nabeshi H, Yoshikawa T, Matsuyama $K$, Nakazato $Y$, Arimori $A$, Isobe M, Tochigi S, Kondoh S, Hirai T, Akase T, Yamashita T, Yamashita K, Yoshida T, Nagano K, Abe Y, Yoshioka Y, Kamada H, Imazawa T, Itoh N, Kondoh M, Yagi K, Mayumi T, Tsunoda S, Tsutsumi Y. Amorphous nanosilicas induce consumptive coagulopathy after systemic exposure. Nanotechnology, 23, 045101 (2012).

16) Nagai H, Okazaki Y, Chew SH, Misawa N, Yamashita Y, Akatsuka S, Ishihara T, Yamashita K, Yoshikawa Y, Yasui H, Jiang L, Ohara H, Takahashi T, Ichihara G, Kostarelos K, Miyata Y, Shinohara H, Toyokuni S. Diameter and rigidity of multiwalled carbon nanotubes are critical factors in mesothelial injury and carcinogenesis. Proc. Natl. Acad. Sci. U.S.A., 108, E1330-E1338 (2011).

17) Nagai H, Okazaki Y, Chew SH, Misawa N, Miyata $Y$, Shinohara $H$, Toyokuni S. Intraperitoneal administration of tangled multiwalled carbon nanotubes of $15 \mathrm{~nm}$ in diameter does not induce mesothelial carcinogenesis in rats. Pathol. Int., 63, 457-462 (2013).

18) Faustman EM, Silbernagel SM, Fenske RA, Burbacher TM, Ponce RA. Mechanisms underlying children's susceptibility to environmental toxicants. Environ. Health Perspect., 108 (Suppl. 1), 13-21 (2000)

19) Wigle DT, Arbuckle TE, Turner MC, Berube A, Yang Q, Liu S, Krewski D. Epidemiologic evidence of relationships between reproductive and child health outcomes and environmental chemical contaminants. J. Toxicol. Environ. Health B Crit. Rev., 11, 373-517 (2008).

20) Koopman-Esseboom C, Weisglas-Kuperus N, de Ridder MA, Van der Paauw CG, Tuinstra LG, Sauer PJ. Effects of polychlorinated biphenyl/dioxin exposure and feeding type on infants' mental and psychomotor development. Pediatrics, 97, 700-706 (1996).

21) Santos IS, Matijasevich A, Domingues MR. Maternal caffeine consumption and infant nighttime waking: prospective cohort study. Pediatrics, 129, 860-868 (2012).

22) Hammoud A, Carrell DT, Gibson M, Sanderson M, Parker-Jones K, Peterson CM. Decreased sperm motility is associated with air pollution in Salt Lake City. Fertil. Steril., 93, 1875-1879 (2010).

23) Volk HE, Lurmann F, Penfold B, Hertz-Picciotto I, McConnell R. Traffic-related air pollution, particulate matter, and autism. JAMA Psychiatry, 70, 71-77 (2013).

24) Li Y, Zhang Y, Yan B. Nanotoxicity overview: nano-threat to sus- ceptible populations. Int. J. Mol. Sci., 15, 3671-3697 (2014).

25) Zhang XF, Park JH, Choi YJ, Kang MH, Gurunathan S, Kim JH Silver nanoparticles cause complications in pregnant mice. Int. J. Nanomedicine, 10, 7057-7071 (2015).

26) Shi H, Magaye R, Castranova V, Zhao J. Titanium dioxide nanoparticles: a review of current toxicological data. Part. Fibre Toxicol., 10, 15 (2013).

27) Liu Y, Li H, Xiao K. Distribution and biological effects of nanoparticles in the reproductive system. Curr. Drug Metab., 17, 478-496 (2016).

28) Girardi G, Redecha P, Salmon JE. Heparin prevents antiphospholipid antibody-induced fetal loss by inhibiting complement activation. Nat. Med., 10, 1222-1226 (2004).

29) Hossain N, Schatz F, Paidas MJ. Heparin and maternal fetal interface: why should it work to prevent pregnancy complications? Thromb. Res., 124, 653-655 (2009).

30) Shirasuna K, Usui F, Karasawa T, Kimura H, Kawashima A, Mizukami H, Ohkuchi A, Nishimura S, Sagara J, Noda T, Ozawa K, Taniguchi S, Takahashi M. Nanosilica-induced placental inflammation and pregnancy complications: Different roles of the inflammasome components NLRP3 and ASC. Nanotoxicology, 9, 554-567 (2015).

31) Higashisaka K, Kunieda A, Iwahara $Y$, Tanaka K, Nagano K, Mukai Y, Kamada H, Tsunoda S, Yoshioka Y, Tsutsumi Y. Neutrophilia due to silica nanoparticles induces release of double-stranded DNA. J. Nanomed. Nanotechnol., 5, 1000236 (2014).

32) Kolaczkowska E, Kubes P. Neutrophil recruitment and function in health and inflammation. Nat. Rev. Immunol., 13, 159-175 (2013).

33) Gartner LM, Morton J, Lawrence RA, Naylor AJ, O'Hare D, Schanler RJ, Eidelman AI, American Academy of Pediatrics Section on Breastfeeding. Breastfeeding and the use of human milk. Pediatrics, 115, 496-506 (2005).

34) Focant JF, Frery N, Bidondo ML, Eppe G, Scholl G, Saoudi A, Oleko A, Vandentorren S. Levels of polychlorinated dibenzo- $p$-dioxins, polychlorinated dibenzofurans and polychlorinated biphenyls in human milk from different regions of France. Sci. Total Environ., 452-453, 155-162 (2013).

35) Rivezzi G, Piscitelli P, Scortichini G, Giovannini A, Diletti G, Migliorati G, Ceci R, Rivezzi G, Cirasino L, Carideo P, Black DM, Garzillo C, Giani U. A general model of dioxin contamination in breast milk: results from a study on 94 women from the Caserta and Naples areas in Italy. Int. J. Environ. Res. Public Health, 10, 5953-5970 (2013).

36) Zhang C, Zhai S, Wu L, Bai Y, Jia J, Zhang Y, Zhang B, Yan B. Induction of size-dependent breakdown of blood-milk barrier in lactating mice by $\mathrm{TiO}_{2}$ nanoparticles. PLoS ONE, 10, e0122591 (2015).

37) Gao X, Yin S, Tang M, Chen J, Yang Z, Zhang W, Chen L, Yang B, Li Z, Zha Y, Ruan D, Wang M. Effects of developmental exposure to $\mathrm{TiO}_{2}$ nanoparticles on synaptic plasticity in hippocampal dentate gyrus area: an in vivo study in anesthetized rats. Biol. Trace Elem. Res., 143, 1616-1628 (2011).

38) Melnik EA, Buzulukov YP, Demin VF, Demin VA, Gmoshinski IV, Tyshko NV, Tutelyan VA. Transfer of silver nanoparticles through the placenta and breast milk during in vivo experiments on rats. Acta Naturae, 5, 107-115 (2013).

39) Franci G, Falanga A, Galdiero S, Palomba L, Rai M, Morelli G, Galdiero M. Silver nanoparticles as potential antibacterial agents. Molecules, 20, 8856-8874 (2015).

40) Contado C. Nanomaterials in consumer products: a challenging analytical problem. Front Chem., 3, 48 (2015).

41) Ramdhan DH, Ito Y, Yanagiba Y, Yamagishi N, Hayashi Y, Li C, Taneda S, Suzuki AK, Watanabe G, Taya K, Kamijima M, Nakajima T. Nanoparticle-rich diesel exhaust may disrupt testosterone biosynthesis and metabolism via growth hormone. Toxicol. Lett., 191, 103-108 (2009). 
42) Gromadzka-Ostrowska J, Dziendzikowska K, Lankoff A, Dobrzynska $\mathrm{M}$, Instanes $\mathrm{C}$, Brunborg $\mathrm{G}$, Gajowik A, Radzikowska J, Wojewodzka M, Kruszewski M. Silver nanoparticles effects on epididymal sperm in rats. Toxicol. Lett., 214, 251-258 (2012).

43) Sleiman HK, Romano RM, Oliveira CA, Romano MA. Effects of prepubertal exposure to silver nanoparticles on reproductive parameters in adult male Wistar rats. J. Toxicol. Environ. Health A, 76, 1023-1032 (2013).

44) Balasubramanian SK, Jittiwat J, Manikandan J, Ong CN, Yu LE, Ong WY. Biodistribution of gold nanoparticles and gene expression changes in the liver and spleen after intravenous administration in rats. Biomaterials, 31, 2034-2042 (2010).

45) van der Zande M, Vandebriel RJ, Van Doren E, Kramer E, Herrera Rivera Z, Serrano-Rojero CS, Gremmer ER, Mast J, Peters RJ, Hollman PC, Hendriksen PJ, Marvin HJ, Peijnenburg AA, Bouwmeester H. Distribution, elimination, and toxicity of silver nanoparticles and silver ions in rats after 28-day oral exposure. ACS Nano, 6, 7427-7442 (2012).

46) Morishita Y, Yoshioka Y, Satoh H, Nojiri N, Nagano K, Abe Y, Kamada H, Tsunoda S, Nabeshi H, Yoshikawa T, Tsutsumi Y. Distribution and histologic effects of intravenously administered amorphous nanosilica particles in the testes of mice. Biochem. Biophys. Res. Cотmun., 420, 297-301 (2012).

47) Setyawati MI, Tay CY, Chia SL, Goh SL, Fang W, Neo MJ, Chong HC, Tan SM, Loo SC, Ng KW, Xie JP, Ong CN, Tan NS, Leong DT. Titanium dioxide nanomaterials cause endothelial cell leakiness by disrupting the homophilic interaction of VE-cadherin. Nat. Commun., 4, 1673 (2013).

48) Yoshida T, Yoshioka Y, Matsuyama K, Nakazato Y, Tochigi S, Hirai T, Kondoh S, Nagano K, Abe Y, Kamada H, Tsunoda S, Nabeshi H, Yoshikawa T, Tsutsumi Y. Surface modification of amorphous nanosilica particles suppresses nanosilica-induced cytotoxicity, ROS generation, and DNA damage in various mammalian cells. Biochem. Biophys. Res. Commun., 427, 748-752 (2012).

49) Yoshida T, Yoshioka Y, Morishita Y, Aoyama M, Tochigi S, Hirai T, Tanaka K, Nagano K, Kamada H, Tsunoda S, Nabeshi H, Yoshikawa T, Higashisaka K, Tsutsumi Y. Protein corona changes mediated by surface modification of amorphous silica nanoparticles suppress acute toxicity and activation of intrinsic coagulation cascade in mice. Nanotechnology, 26, 245101 (2015).

50) Morishita Y, Yoshioka Y, Takimura Y, Shimizu Y, Namba Y, Nojiri N, Ishizaka T, Takao K, Yamashita F, Takuma K, Ago Y, Nagano K, Mukai Y, Kamada H, Tsunoda S, Saito S, Matsuda T, Hashida M, Miyakawa T, Higashisaka K, Tsutsumi Y. Distribution of Silver Nanoparticles to Breast Milk and Their Biological Effects on Breast-Fed Offspring Mice. ACS Nano, 10, 8180-8191 (2016).

51) Cedervall T, Lynch I, Lindman S, Berggard T, Thulin E, Nilsson $\mathrm{H}$, Dawson KA, Linse S. Understanding the nanoparticle-protein corona using methods to quantify exchange rates and affinities of proteins for nanoparticles. Proc. Natl. Acad. Sci. U.S.A., 104, 2050-2055 (2007).

52) Nel AE, Madler L, Velegol D, Xia T, Hoek EM, Somasundaran P, Klaessig F, Castranova V, Thompson M. Understanding biophysicochemical interactions at the nano-bio interface. Nat. Mater., 8 , 543-557 (2009)

53) Higashisaka K, Yoshioka Y, Yamashita K, Morishita Y, Fujimura M, Nabeshi H, Nagano K, Abe Y, Kamada H, Tsunoda S, Yoshikawa T, Itoh N, Tsutsumi Y. Acute phase proteins as biomarkers for predicting the exposure and toxicity of nanomaterials. Biomaterials, 32, 3-9 (2011).

54) Higashisaka K, Yoshioka Y, Yamashita K, Morishita Y, Pan H, Ogura T, Nagano T, Kunieda A, Nagano K, Abe Y, Kamada H, Tsunoda S, Nabeshi H, Yoshikawa T, Tsutsumi Y. Hemopexin as biomarkers for analyzing the biological responses associated with exposure to silica nanoparticles. Nanoscale Res. Lett., 7, 555 (2012).

55) Nagano T, Higashisaka K, Kunieda A, Iwahara Y, Tanaka K, Nagano K, Abe Y, Kamada H, Tsunoda S, Nabeshi H, Yoshikawa T, Yoshioka Y, Tsutsumi Y. Liver-specific microRNAs as biomarkers of nanomaterial-induced liver damage. Nanotechnology, 24, 405102 (2013).

56) Hirai $T$, Yoshioka $Y$, Izumi $N$, Ichihashi $K$, Handa $T$, Nishijima N, Uemura E, Sagami K, Takahashi H, Yamaguchi M, Nagano K, Mukai Y, Kamada H, Tsunoda S, Ishii KJ, Higashisaka K, Tsutsumi Y. Metal nanoparticles in the presence of lipopolysaccharides trigger the onset of metal allergy in mice. Nat. Nanotechnol., 11, 808-816 (2016).

57) Kolosnjaj-Tabi J, Just J, Hartman KB, Laoudi Y, Boudjemaa S, Alloyeau D, Szwarc H, Wilson LJ, Moussa F. Anthropogenic Carbon Nanotubes Found in the Airways of Parisian Children. EBioMedicine, 2, 1697-1704 (2015).

58) Pele LC, Thoree V, Bruggraber SF, Koller D, Thompson RP, Lomer MC, Powell JJ. Pharmaceutical/food grade titanium dioxide particles are absorbed into the bloodstream of human volunteers. Part. Fibre Toxicol., 12, 26 (2015).

59) Pace HE, Rogers NJ, Jarolimek C, Coleman VA, Gray EP, Higgins CP, Ranville JF. Single particle inductively coupled plasma-mass spectrometry: a performance evaluation and method comparison in the determination of nanoparticle size. Environ. Sci. Technol., 46, 12272-12280 (2012).

60) Tuoriniemi J, Cornelis G, Hassellov M. Size discrimination and detection capabilities of single-particle ICPMS for environmental analysis of silver nanoparticles. Anal. Chem., 84, 3965-3972 (2012).

61) Huynh KA, Siska E, Heithmar E, Tadjiki S, Pergantis SA. Detection and quantification of silver nanoparticles at environmentally relevant concentrations using asymmetric flow field-flow fractionation online with single particle inductively coupled plasma mass spectrometry. Anal. Chem., 88, 4909-4916 (2016). 